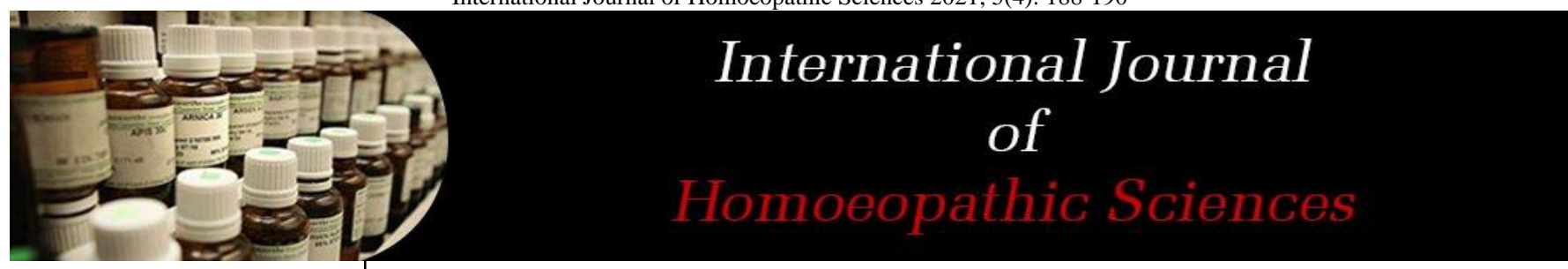

E-ISSN: 2616-4493 P-ISSN: 2616-4485 www.homoeopathicjournal.com IJHS 2021; 5(4): 188-190 Received: 22-08-2021 Accepted: 24-09-2021

Dr. Nivedhitha S M.D. (Hom), M.Sc (C\&P) Consultant, No. 112, Iyyanar Avenue, Oil Mill, IRN Backside, Thiruvallur, Tamil Nadu, India
Corresponding Author: Dr. Nivedhitha $\mathrm{S}$ M.D. (Hom), M.Sc (C\&P Consultant, No. 112, Iyyanar Avenue, Oil Mill, IRN Backside, Thiruvallur, Tamil Nadu, India

\title{
A case of sinusitis with hyperhidrosis treated homoeopathically: A case report
}

\section{Dr. Nivedhitha $S$}

DOI: https://doi.org/10.33545/26164485.2021.v5.i4c.472

Abstract

Some Patient visits the physician only for their primary complaints troubling them and gives least importance to their general symptoms where it is most important criteria to be noted for a homoeopathic physician. "The things that are general are the first in importance. Where there are no generals we can expect no cures" says Kent ${ }^{[1]}$. Holistic approach to the patient is the speciality of Homoeopathy. The cause effect relationship of the patient is to be established. There is no expression of symptom without a cause. Underlying cause is to be treated ${ }^{[2]}$.

Keywords: general symptoms (mental, physical), sinusitis, hyperhidrosis, cause and effect relationship

\section{Introduction}

A male patient aged 30 years came with the complaints of pain in right side of head since 20 years. Now increased since $1 \frac{1}{2}$ years.

\section{Presenting complaint}

A male patient aged 30 years came with complaints of pain in right side of head since 20 years. Now increased since $1 \frac{1}{2}$ years. Pricking type of pain ${ }^{2+}$ with heaviness of head. Post nasal dripping present. Sleep disturbed due to complaints. Associated symptoms are Excessive sweating ${ }^{2+}$ on skin palms and soles since birth.

\section{History of presenting complaint}

Patient complaints of pain in right side of head since 20 years on \& off attack and frequency $2-3$ attacks in a year. Now increased since 11/2 years and frequency is daily. Pricking type of pain $^{2+}$. Heaviness of head is present. Sneezing occ. Post nasal dripping is present. Burning sensation of face with nose block is present. Complaints generally worse by taking cold drinks $^{2+}$, dust, change of climate and better by allopathic medication.

\section{Associated complaints}

Patient complaints of excessive sweating on palms and soles since birth. Always feels his hand is moist. Complaints worse by getting anxious ${ }^{2+}$ and doing his daily work ${ }^{2+}$. He feels that he is embarrassed to shake his hand to others were actually his profession demands. Always he has a peeling of skin on winter season.

\section{Past history}

Medical history: Primary complex in 5 yrs of age.

Treatment history: Taken allopathic treatment for primary complex and presenting complaints.

Family history: Father has similar complaints with DNS

Physical Generals

- Appetite: Good. 3times a day

- Thirst: 21 a day

- Desire: sweet ${ }^{\mathrm{s} 2+}$, fruits

- Aversion: Vegetables 
- Bowels: regular. Once daily

- Bladder: 2 times/ day

- Sleep: disturbed due to complaints

- Thermal state: likes summer season, doesn't want fan, likes open air, covers fully while sleeping, and takes bath in tepid water. Chilly patient.

- Perspiration: profuse on hand, feet and soles

\section{Mental generals}

- Hard working

- Dyslexia

- Anxious when about to start a work

- Fastidious.

- Easily gets angered when something goes wrong

\section{General physical examination}

Moderately built and well nourished. No pallor, cyanosis, clubbing, oedema, jaundice, lymphadenopathy

\section{Vital signs}

Temp.: Afebrile RR: $18 / \mathrm{min}$

PR: 69/min

BP: $120 / 100 \mathrm{~mm} \mathrm{Hg}$

\section{On examination}

- Right side frontal and maxillary sinuses are tender

- Nasal septum deviated to right side

\section{Analysis and Evaluation of symptoms}

- Hard working

- Anxious when about to start a work

- Fastidious.

- Easily gets angered when something goes wrong

- Desire: sweets, fruits

- Thermally: chilly patient

- Excessive sweating on palms < anxious

- Pricking pain in right side of face

- Burning sensation in face

- Post nasal dripping

Table 1: Totality of symptoms \& Repertorial totality

\begin{tabular}{|c|c|}
\hline Hardworking & Mind - work - desire - for mental \\
\hline Dyslexia & Mind - mistakes - makes - reading \\
\hline Anxious when about to start a work & Mind - Anxiety - Anticipating - Engagement, an Mind - Anxiety - Anticipating \\
\hline Fastidious & Mind - Fastidious \\
\hline Easily gets angered when something goes wrong & Mind - Anger - Irascibility - tendency - easily \\
\hline Desire: sweets, fruits & Generalities - Food and drinks - Sweets - desire \\
Generalities - Food and drinks - Fruits - desire
\end{tabular}

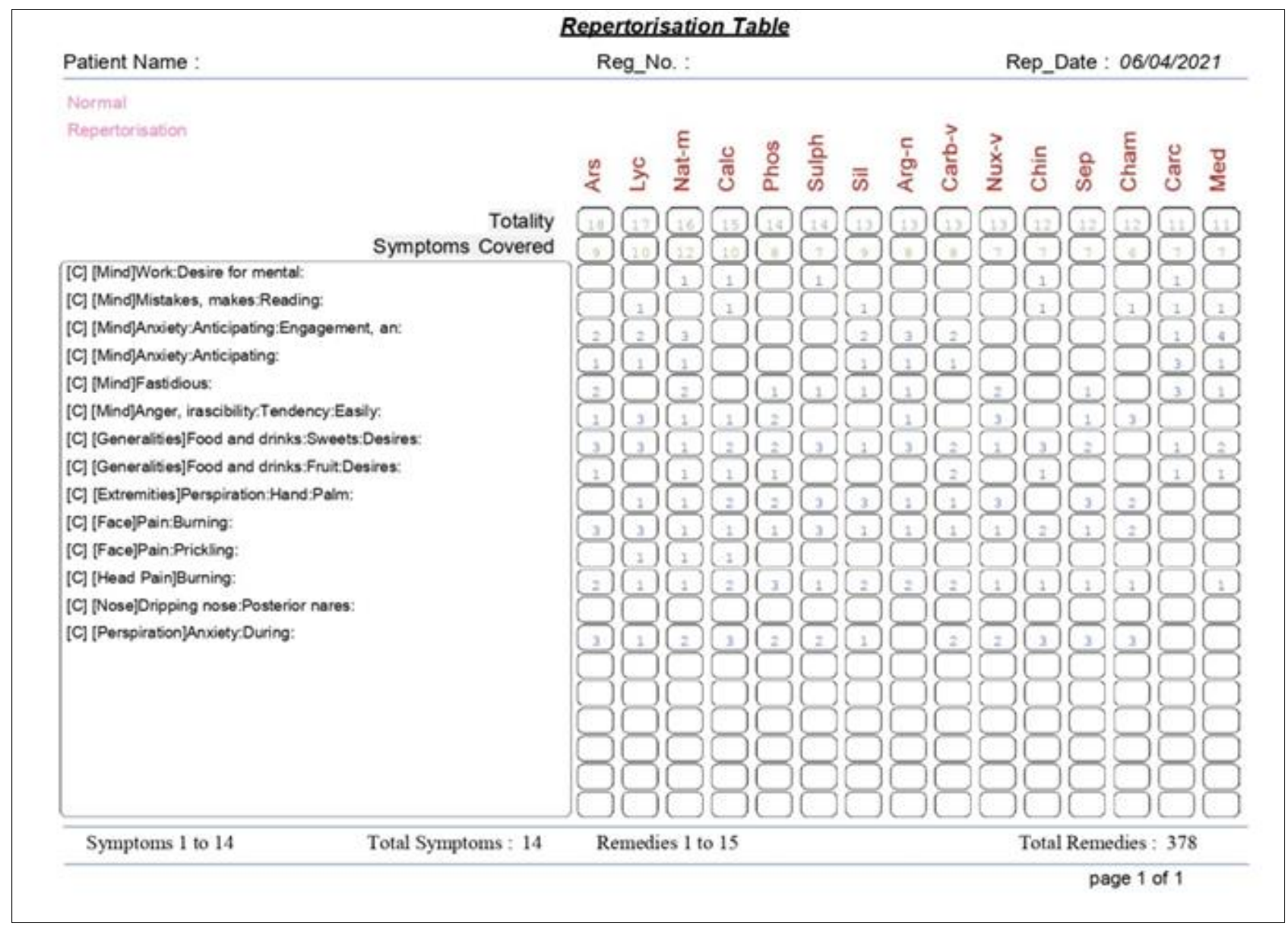

Fig: Repertoristion Table 


\section{Repertorial result}

- Arsenicum album - 18/9

- Lycopodium - 17/10

- Natrum mur - $16 / 12$

- Calcarea carb - 15/10
- $\quad$ Phosphorous - $14 / 8$

Prescription

1. Arsenicum album 200 / 1dose HS Weekly

2. Sac lac 4-0-4 For 1 week

Table 2: Follow up

\begin{tabular}{|c|c|c|}
\hline Date & Symptoms & \multicolumn{1}{c|}{ Prescription } \\
\hline $04 / 05 / 2021$ & $\begin{array}{c}\text { Complaints of excessive sweating of palms and soles are completely absent. Anxiety } \\
\text { reduced. Patient has completely forgotten about his sweating of palms. Sleep improved. } \\
\text { Complaints of headache and heaviness are still same. Burning sensation of face } \\
\text { improved. Nose block present. On examination mild tenderness of sinuses was present. }\end{array}$ & $\bullet \begin{array}{l}\text { Arsenicum album } 200 \text { one dose } \\
\text { Complaints of headache and heaviness are still same. Post nasal dripping is present. Nose } \\
\text { block is present. Burning sensation of face is better. When enquired patient said the } \\
\text { complaints increasing 1 1/2 years due to tooth extraction which was due to an improper } \\
\text { filling. Right upper molar tooth extracted and which has not closed properly. On } \\
\text { examination sinuses were tender. }\end{array}$ \\
\hline $08 / 06 / 2021$ & Sac lac 4-0-4 for two weeks \\
\hline $06 / 07 / 2021$ & $\begin{array}{c}\text { Complaints of headache and heaviness are better. No post nasal dripping. Nose block } \\
\text { absent. Sleep improved. On examination no tenderness on sinuses. Sweating of palms is } \\
\text { completely absent. }\end{array}$ & $\bullet$ Sac lac 4-0-4 for two weeks \\
\hline
\end{tabular}

\section{Conclusion}

Patient was completely relieved by Arsenicum album 200 where it was prescribed constitutionally. Hyperhidrosis is the constitutional problem in this patient which should have a holistic approach in treating with Homoeopathy. Whereas the complaints of sinusitis need a cause to be established. Here the cause of sinusitis is tooth extraction which is failed to elicit and later it has been enquired. It is the maintaining cause in the patient. Based on that Kali bichromicum 200 one dose has been prescribed. Maintaining cause plays a more value in treating the patient. Thus the cause effect relationship should be traced and to be treated accordingly [3].

\section{Reference}

1. Lectures on homeopathic philosophy: J.T. Kent; B. Jain publishers.

2. Comprehensive study of Organon An attempt to understand the Organon of Medicine as Scientific Treatise: Dr. G. Nagendra Babu; B. Jain publishers.

3. Hahnemann S, Boericke W, Dudgeon R. Organon of medicine. New Delhi: B. Jain Publishers. 